\title{
Placing Greenland ice sheet ablation measurements in a multi-decadal context
}

\author{
Dirk van As, Robert S. Fausto, John Cappelen, Roderik S.W. van de Wal, Roger J. Braithwaite, \\ Horst Machguth and the PROMICE project team*
}

In recent years, the Greenland ice sheet has been losing mass at an average rate of $262 \pm 21 \mathrm{Gt} \mathrm{yr}^{-1}(2007-2011$; Andersen et al. 2015). Part of this mass loss was due to increases in melt, reducing the surface mass budget (Enderlin et al. 2014). Also, the acceleration of many marine-terminating outlet glaciers increased the dynamic mass loss (Rignot $e t$ al. 2008). Both mass-loss mechanisms are linked to recent increases in atmospheric and oceanic temperatures (Dutton et al. 2015). For instance, in summer 2012 Greenland experienced exceptionally warm atmospheric conditions, causing nearly the entire ice-sheet surface to melt for two periods of several days (Nghiem et al. 2012) and contributing to the largest annual ice-sheet mass loss on record (Khan et al. 2015). This is in contrast to a return to more average conditions in 2015 (Tedesco et al. in press).

In 2007 the Programme for Monitoring of the Greenland Ice Sheet (PROMICE) was initiated to monitor both the surface mass budget and dynamic contributions to mass change. For the monitoring, c. 20 automatic weather stations were distributed over eight regions of the Greenland ice sheet (Fig. 1), primarily in the ablation area where surface melting is most prominent (Van As et al. 2011). These stations record a suite of meteorological and radiative variables that allow for surface-energy budget closure, and reveal the relative importance of the different energy fluxes contributing to melting. Each station also monitors ablation by sonic height rangers, pressure transducers and ablation stakes (Fausto et al. 2012).

Table 1 shows that the 2015 melt season yielded ablation totals below the PROMICE average (i.e. reduced surface mass loss) in all regions except the two northernmost ones: KPC and THU. Along the south-western ice sheet margin the 2015 ablation anomalies appear to be one third below average. However, what has to be accounted for in the interpretation is that the PROMICE observational period contained several warm years and summers. Figure 2 illustrates that there have been considerable fluctuations in atmospheric temperatures at Greenland coastal sites with continuous records dating back to the 19th century. The PROMICE observational period distinctly classifies as one with aboveaverage temperatures, both in the relatively warm south and colder north (Fig. 2). This is also likely to imply above-average ablation, and thus biased PROMICE ablation anomalies. It is therefore more insightful to evaluate recent ablation measurements in the context of a more representative

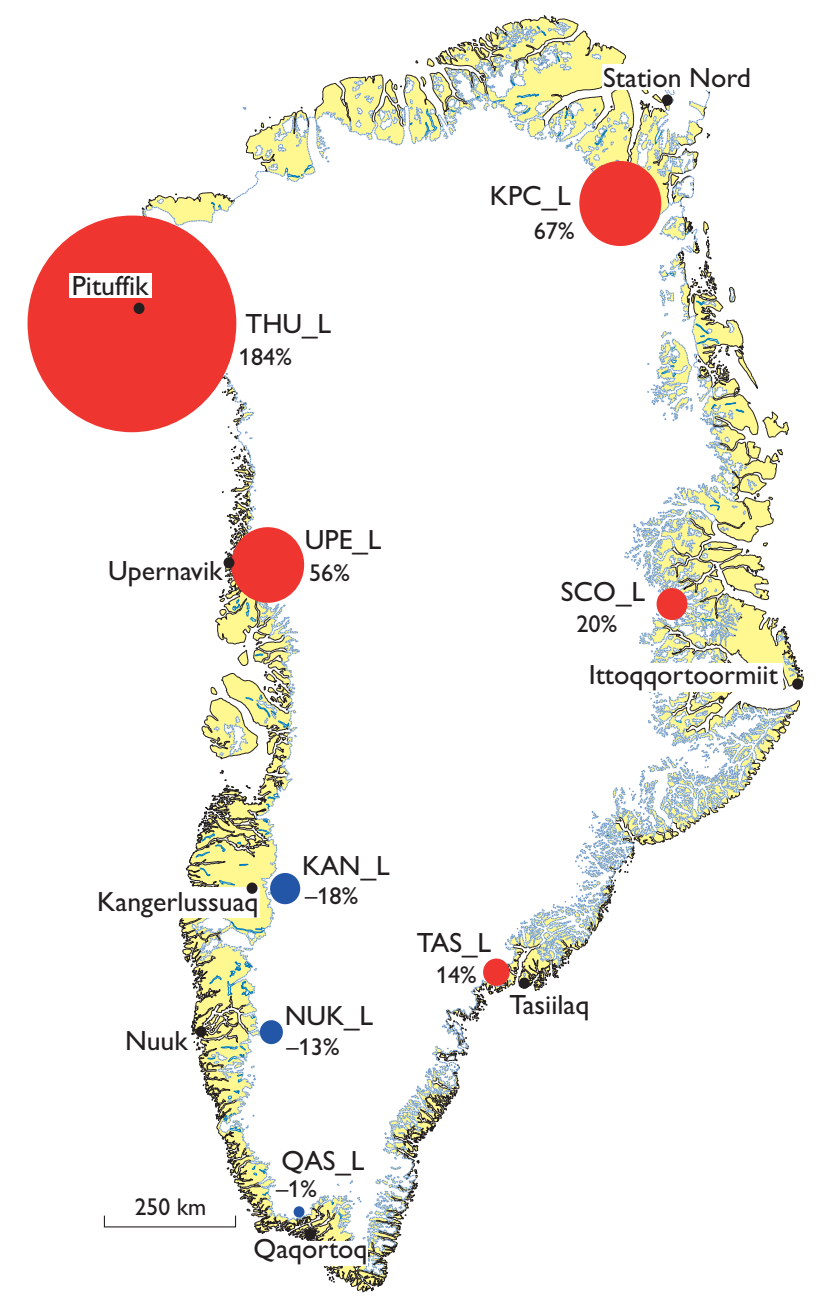

Fig. 1. Map of Greenland with 2015 ablation anomaly values referenced to the 1961-1990 period at the lower (suffix L) PROMICE weather station sites. Black dots indicate DMI weather stations selected for this study. 
Table 1. Temperature and ablation statistics for the PROMICE weather station sites

\begin{tabular}{|c|c|c|c|c|c|c|c|c|}
\hline & KPC_L & SCO_L & TAS_L & QAS_L & NUK_L & KAN_L & UPE_L & THU_L \\
\hline Temperature JJA 1961-1990 ( $\left.{ }^{\circ} \mathrm{C}\right)$ & 1.7 & 2.7 & 5.5 & 6.5 & 5.5 & 9.2 & 4.1 & 3.9 \\
\hline Temperature JJA 2008-2015 $\left({ }^{\circ} \mathrm{C}\right)$ & 2.8 & 5.0 & 6.7 & 7.3 & 7.5 & 10.5 & 6.3 & 5.3 \\
\hline Annual net ablation PROMICE (m ice eq.) & 2.2 & 3.2 & 3.6 & 6.4 & 5.5 & 3.8 & 2.6 & 1.8 \\
\hline 2015 ablation anomaly ref. to the PROMICE average (\% & \%) 7 & -1 & -14 & -20 & -31 & -34 & -12 & 30 \\
\hline Annual net ablation 1961-1990 (m ice eq.) & 1.4 & 2.7 & 2.7 & 5.1 & 4.4 & 3.1 & 1.5 & 0.8 \\
\hline Temperature sensitivity (line slope) (m ice eq. ${ }^{\circ} \mathrm{C}^{-1}$ ) & 0.71 & 0.25 & 0.79 & 1.23 & 0.64 & 0.63 & 0.55 & 0.89 \\
\hline Correlation of linear fit ( $r$ ) & 0.59 & 0.50 & 0.60 & 0.75 & 0.83 & 0.71 & 0.81 & 0.94 \\
\hline RMSD* of linear fit ( $m$ ice eq.) & 0.5 & 0.3 & 0.6 & 0.9 & 0.6 & 0.5 & 0.3 & 0.2 \\
\hline Uncertainty ablation calculation ( $\mathrm{m}$ ice eq.) & 0.6 & 0.4 & 0.7 & 0.9 & 0.6 & 0.6 & 0.5 & 0.4 \\
\hline 2015 ablation anomaly referenced to $1961-1990(\%)$ & $67 \pm 40$ & $20 \pm 15$ & $14 \pm 25$ & $-1 \pm 18$ & $-13 \pm 15$ & $-18 \pm 19$ & $56 \pm 31$ & $184 \pm 43$ \\
\hline
\end{tabular}

* RMSD: root mean squared differences

climate. Greenland studies often use the 1961-1990 period, during which the ice sheet is assumed to have been in nearsteady state (e.g. Braithwaite et al. 1992; Rignot et al. 2008). The main aim of this study is to reference PROMICE-measured ablation to this 1961-1990 'climate normal'.

\section{Present-day temperatures in a multi- decadal perspective}

In order to determine the 1961-1990 reference climate, we need observational records spanning that period and recent years. The only continuous and (on these time scales) relevant Greenland data series that exist have been recorded in coastal areas, by weather stations of the Danish Meteorological Institute (DMI). For this study we selected those DMI time series that were gathered closest to the PROMICE weather station sites and were initiated before 1961 (Fig. 1). The earliest measurements (primarily of air temperature) were taken in the 1700 s; several continuous records date back to the mid to late 1800s (Fig. 2).

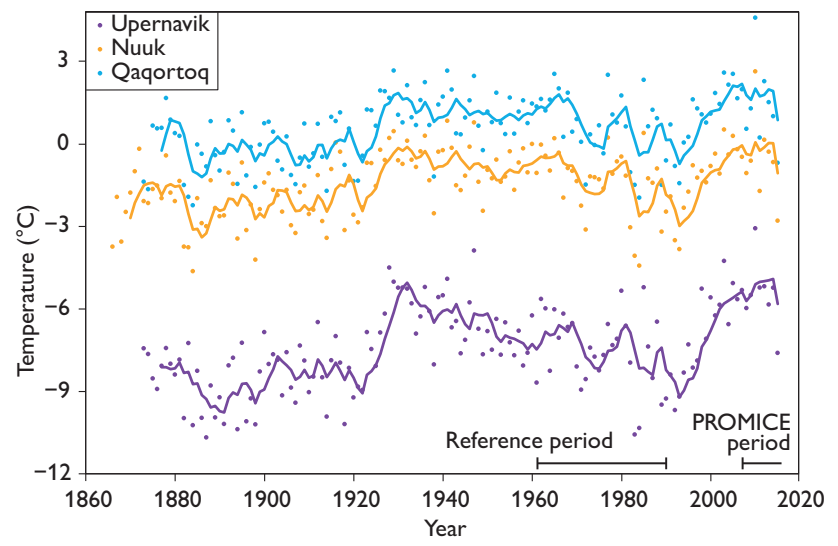

Fig. 2. Annual (dots) and five-year (lines) running-mean temperatures at the three longest-running DMI measurement sites used in this study. Arrows indicate the 1961-1990 reference period and the PROMICE period (2007-present).
Ice sheet surface melting occurs predominantly in summer, so for the purpose of this study we calculated the average June-July-August (JJA) temperature for each year, following e.g. Braithwaite et al. (1992). Temperature anomalies were calculated by subtracting the 1961-1990 JJA average. We obtained monthly average data from the DMI technical report 15-04 (Cappelen 2015) and supplemented these with 2015 data.

Table 1 shows that at all selected DMI sites the JJA temperature during the PROMICE observational period is higher than in the reference period. The smallest difference is found at Qaqortoq in South Greenland $\left(0.8^{\circ} \mathrm{C}\right)$, and the largest at Ittoqqortoormiit in the east $\left(2.4^{\circ} \mathrm{C}\right)$. For the years with PROMICE annual ablation values (2008-2015), only three out of a total of 64 station years $(5 \%)$ had negative JJA temperature anomalies indicative of conditions colder than during the reference period, emphasising the need for a well-defined context.

\section{Measurements of ice ablation along the ice-sheet margin}

The first PROMICE weather stations were established in 2007 (Van As et al. 2011), thus providing annual net-ablation values since 2008 (i.e. end of melt season 2007 until end of melt season 2008). At any given site five to eight years' worth of ablation data exist. In this study we only make use of the eight weather stations that are located closest to the ice-sheet margin (all with suffix 'L' for 'lower'). At these elevations, summer ablation is much larger than winter accumulation, resulting in stronger correlations between net ablation and atmospheric temperature anomalies than higher on the ice sheet where ablation becomes an increasingly small contributor to the surface-mass budget. Selecting the 'lower' PROMICE stations provides us with a total of 56 ablation years. 


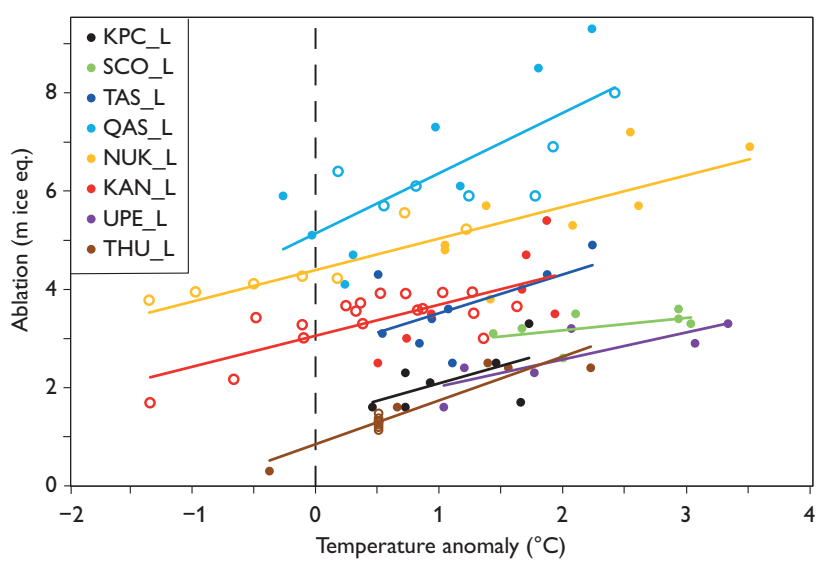

Fig. 3. Measured annual net ablation from PROMICE (dots) and other projects (circles) plotted against the regional temperature anomaly referenced to the 1961-1990 period. Lines illustrate linear least-squares fits.

We supplement the PROMICE data with older ablation observations gathered in close proximity to the current station locations, at identical elevations, and covering the entire 'hydrological' year, i.e. referenced to the end of the melt season. At four station sites, such measurements from before 2008 exist, namely at QAS_L for 2001-2007 (e.g. Podlech et al. 2004), at NUK_L for 1981-1987 (e.g. Braithwaite et al. 1992), at KAN_L since 1991 (Van de Wal et al. 2012) and at THU_L in 1954 (Schytt 1955). These 40 historical measurements bring our grand total to 96 ablation years.

\section{Present-day ablation in a multi-decadal perspective}

In this study we relate annual net-ablation values to JJA temperatures following e.g. Braithwaite et al. (1992), but without precipitation due to lacking DMI data. Besides, differences in precipitation at the DMI and PROMICE sites can be large due to spatial heterogeneity. In Fig. 3 we plotted the annual net-ablation values against the temperature anomalies calculated from DMI weather stations in the region. At all sites, the ablation totals typically increase with temperature, as indicated by the linear least-squares fit lines. The slopes of these lines are the regional temperature sensitivities, which is relatively low at the SCO_L site with $0.25 \mathrm{~m}$ ice equivalent (eq.) ${ }^{\circ} \mathrm{C}^{-1}$, and high for QAS_L where roughly an additional $1.2 \mathrm{~m}$ of ice would ablate for every degree JJA temperature increase (Table 1). We find an average temperature sensitivity of the ice-marginal area of $0.71 \pm 0.28 \mathrm{~m}$ ice eq. ${ }^{\circ} \mathrm{C}^{-1}$ (standard deviation given), rather similar to the value of $0.5 \mathrm{~m}$ water eq. ${ }^{\circ} \mathrm{C}^{-1} \mathrm{men}-$ tioned in e.g. Braithwaite et al. (1992).

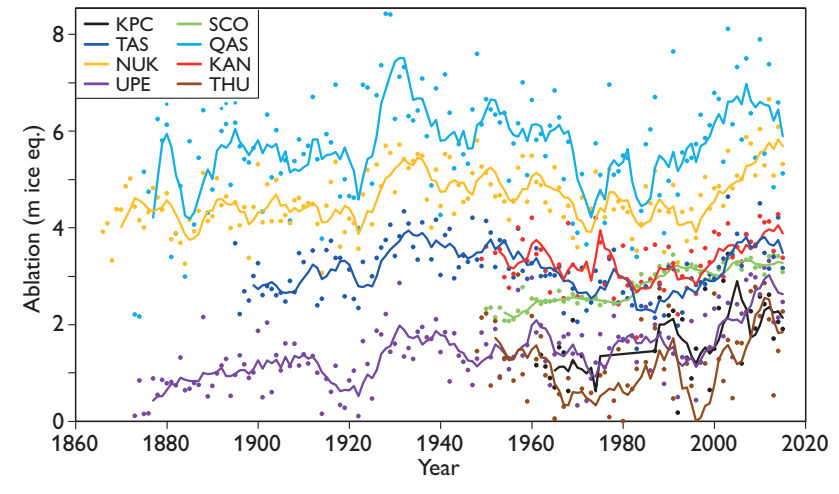

Fig. 4. Estimated yearly (dots) and five-yearly (lines) net ablation for sites currently instrumented by PROMICE.

A key element in this study is the ablation value at which the fitted lines intercept the $0^{\circ} \mathrm{C}$ temperature anomaly line, which for some sites requires extrapolation. The intercept values represent net ablation in the reference climate. Most PROMICE ablation values exceed the intercept values specific to their sites: ablation is larger in recent years than in the reference period. Table 1 shows that the largest relative increase is found at THU_L, where we estimate annual net ablation to have increased by $c .120 \%$. The reference period adjustment for PROMICE ablation values is substantial at all sites (0.6-1.2 $\mathrm{m}$ ice eq., Table 1$)$.

We need to be cautious in the interpretation of these results as the number of data points is still rather small. Furthermore, one cannot expect a perfect correlation between ablation and temperature because: (1) melt is the result of a surplus in energy at the ice-sheet surface, of which only part is provided by atmospheric heat content, (2) the horizontal and vertical distances between the DMI and PROMICE observation sites are considerable, and (3) winter accumulation is part of the net ablation signal but not a function of JJA temperatures. As a measure of uncertainty of reference-period ablation due to the above, we calculate the root mean squared differences (RMSD) between the measured and calculated values. These range from 0.2 to $0.9 \mathrm{~m}$ ice eq. (Table 1 ). To this we add a conservatively chosen measurement uncertainty in the annual net-ablation values of $0.3 \mathrm{~m}$ ice eq. (Fausto et al. 2012), resulting in total uncertainties ranging from 0.4 to $0.9 \mathrm{~m}$ ice eq. The largest uncertainty is found for QAS_L, likely due to interannual variability in winter accumulation and the station's positioning in an irregular, crevassed terrain prior to its $1.5 \mathrm{~km}$ relocation in 2009.

Through the above re-referencing procedure the 2015, ablation anomalies become considerably larger (Table 1, Fig. 1). After reference adjustment, we find positive 
2015 anomalies for all sites except QAS_L, NUK_L and KAN_L, though these do not exceed their uncertainty ranges. The largest anomaly still occurs at THU_L, but is $184 \pm 43 \%$ when referenced to the $1961-1990$ climate, six times larger than the $30 \%$ value when referenced to the PROMICE average.

\section{Approximating past ablation}

The relations found between JJA temperature and annual net ablation in Fig. 3 can be used to estimate ablation from temperature in any year. In Fig. 4 we used these functions for all summers for which DMI temperature data are available - though some of the earlier data were discarded to maintain continuity. We assume the uncertainties listed in Table 1 to apply for these calculations as well, although it should be noted that the derived functions are less well constrained in the range with negative temperature anomalies (Fig. 3).

We conclude that at our study sites annual net ablation is likely to be larger in recent years than during any previous period in the instrumental era, covering up to 150 years. Especially at the more northern locations we find that ablation increases in recent years are large. Yet Fig. 4 suggests that in southern Greenland ablation peaked significantly around 1930. While most of Greenland underwent relatively warm (summer) conditions in the 1930s (Cappelen 2015), this was most notable at the more southern locations, resulting in amplified ablation values according to our estimates. JJA temperatures were higher in 1928 and 1929 than in any other year of the Qaqortoq record, both attaining values of $9.2^{\circ} \mathrm{C}$. This suggests that ablation in those years may have exceeded the largest net ablation measured on the Greenland ice sheet $(9.3 \mathrm{~m}$ ice eq. at QAS_L in 2010), although this is not beyond the uncertainty that accounts for important factors such as winter accumulation.

\section{Acknowledgements}

This is a publication in the framework of the DANCEA-funded Programme for Monitoring of the Greenland Ice Sheet (PROMICE), in col- laboration with several other projects. The KAN stations are funded by the Greenland Analogue Project (GAP). Stake measurements by Utrecht University are funded through the NWO polar programme.

\section{References}

Andersen, M.L. et al. 2015: Basin-scale partitioning of Greenland ice sheet mass balance components (2007-2011). Earth and Planetary Science Letters 409, 89-95.

Braithwaite, R.J., Olesen O.B. \& Thomsen H.H. 1992: Calculated variations of annual ice ablation at the margin of the Greenland ice sheet, West Greenland, 1961-1990. Journal of Glaciology 38 (129), 266-272.

Cappelen, J. (ed.) 2015: Greenland - DMI historical climate data collection 1784-2014. Danish Meteorological Institute Technical Report 15-04, 97 pp.

Dutton, A., Carlson, A.E., Long, A.J., Milne, G.A., Clark, P.U., DeConto, R., Horton, B.P., Rahmstorf, S. \& Raymo, M.E. 2015: Sealevel rise due to polar ice-sheet mass loss during past warm periods. Science 349 (6244) aaa4019.

Enderlin, E.M., Howat, I.M., Jeong, S., Noh, M.-J., Van Angelen, J.H. \& Van den Broeke, M.R. 2014: An improved mass budget for the Greenland ice sheet. Geophysical Research Letters 41 (3), 866-872.

Fausto, R.S., Van As, D., Ahlstrøm, A.P. \& Citterio, M. 2012: Assessing the accuracy of Greenland ice sheet surface ablation measurements by pressure transducer. Journal of Glaciology 58 (212), 1144-1150.

Khan, S.A., Aschwanden, A., Bjørk, A.A.,Wahr, J., Kjeldsen, K.K. \& Kjær, K.H. 2015: Greenland ice sheet mass balance: a review. Reports on Progress in Physics 78, 046801.

Nghiem, S.V. et al. 2012: The extreme melt across the Greenland ice sheet in 2012. Geophysical Research Letters 39, L20502.

Podlech, S., Mayer, C. \& Bøggild, C.E. 2004: Glacier retreat, mass-balance and thinning: Sermilik Glacier, South Greenland. Geografiska Annaler 86A, 305-317.

Rignot, E., Box, J.E., Burgess, E. \& Hanna E. 2008: Mass balance of the Greenland ice sheet from 1958 to 2007. Geophysical Research Letters 35, L20502.

Schytt, V. 1955: Glaciological investigations in the Thule Ramp area. Report Snow, Ice, and Permafrost Research Establishment 28, 88 pp. Corps of Engineers, U.S. Army.

Tedesco, M. et al. in press: Greenland ice sheet [in 'State of the Climate in 2015']. Bulletin of the American Meteorological Society 97(7).

Van As, D., Fausto, R.S. \& PROMICE Project Team 2011: Programme for Monitoring of the Greenland Ice Sheet (PROMICE): first temperature and ablation records. Geological Survey of Denmark and Greenland Bulletin 23, 73-76.

Van de Wal, R.S.W., Boot, W., Smeets, C.J.P.P., Snellen, H., Van den Broeke, M.R. \& Oerlemans, J. 2012: Twenty-one years of mass balance observations along the K-transect, West Greenland. Earth Systems Science Data 4, 31-35.

\footnotetext{
Authors' addresses

D.v.A., R.S.F., H.M., C.C., J.E.B., A.M.S., A.P.A., K.H., M.C. \& S.B.A., Geological Survey of Denmark and Greenland, Øster Voldgade 10, DK-1350 Copenhagen K, Denmark. E-mail: dva@geus.dk

H.M. also at Department of Geography, University of Zurich, Winterthurerstrasse 190, 8057 Zürich, Switzerland.

K.H. also at Natural History Museum, Copenhagen University, Øster Voldgade 5, DK-1350 Copenhagen K, Denmark.

J.C., Danish Meteorological Institute, Lyngbyvej 100, DK-2100 Copenhagen Ø, Denmark.

R.S.W.v.d.W., Institute for Marine and Atmospheric Research, Utrecht University, Princetonplein 5, 3584 CC Utrecht, The Netherlands.

R.J.B., School of Environment, University of Manchester, Oxford Road, Manchester M13 9PL, UK.
} 